\title{
Development of a Lewis-Based Catalytic System for Biodiesel Production: from a Batch Laboratory Scale to a Continuous Pilot Plant
}

\author{
Paulo A. Z. Suarez* and Fabio M. da Silva \\ INCT-Catálise, Instituto de Química, Universidade de Brasília, Campus Universitário Darcy Ribeiro, \\ CP 4478, 70904-970 Brasília-DF, Brazil
}

\begin{abstract}
O desenvolvimento de um processo ou produto industrial envolve diferentes passos: (i) identificar a necessidade de um novo produto ou processo; (ii) pesquisar no laboratório, em escala de vidraria, um caminho que leve ao produto ou processo desejado; (iii) construir uma planta piloto em escala de laboratório; (iv) scale up uma ou mais vezes a planta piloto; (v) construir e iniciar a produção industrial. Do início de 2002 até o fim de 2011, o Laboratório de Materiais e Combustíveis (Instituto de Química, Universidade de Brasília) dedicou-se ao desenvolvimento de um processo alternativo para produzir biodiesel. O objetivo deste trabalho é descrever todo este desenvolvimento, a fim de mostrar o longo caminho para se construir uma planta piloto em escala de laboratório.
\end{abstract}

The development of an industrial process or product involves different steps: $(i)$ identify the necessity of a new product or process; (ii) research in glassware scale to find a way that leads to the desired product or process; (iii) build up and optimize a laboratory pilot plant; (iv) scale up one or more times the pilot plant; $(v)$ build up an industrial plant and start up a commercial production. From the beginning of 2002 to the end of 2011, the Laboratory of Materials and Fuels (Institute of Chemistry, University of Brasília) has focused in the development of an alternative process to produce biodiesel. The aim of this account paper is to describe all this development in order to show the long way to achieve a laboratory pilot plant scale.

Keywords: biodiesel, process development, pilot plant

\section{Introduction}

We repeat the simple act of buying a product in the market so often that we hardly think about how that good comes to the shelves. Usually it hides a long, hard and sometimes beautiful history involving research and development before it becomes a commercial product. Indeed, different steps are involved in a product development, as it can be depicted from Figure 1. The first step is the motivation, it means, the necessity of a new product or a new or optimized process, which defines the goal of the entire development. Thus, when the goal is well defined, a really hard work is done by chemists in the laboratory in order to find a way that leads to the desired product, which may be a chemical reaction and/ or a physical process, such as an extraction.

Then, without significantly changing the scale, the development of a laboratory scale pilot plant starts up building the concept of the industrial plant. Indeed, the usual glassware from the laboratory are changed by minimalistic equipments that have the same design than those would be used in industries. When the laboratory pilot plant is optimized the process is scaled up by building one or more industrial pilot plants increasing in each one the scale. Finally, the industrial plant is built and starts the commercial step. Of course, because of economical reasons most of the efforts expended in the laboratory glassware step results only in a bunch of academic thesis, scientific articles or a company internal report and a really minority would end up to the market.

From the beginning of 2002 to the end of 2011, the Laboratory of Materials and Fuels (Institute of Chemistry, University of Brasília) has focused in the development of an alternative process to produce biodiesel. The aim of this account paper is to describe all this development in order to show the long way to achieve a laboratory pilot plant scale.

*e-mail: psuarez@unb.br 


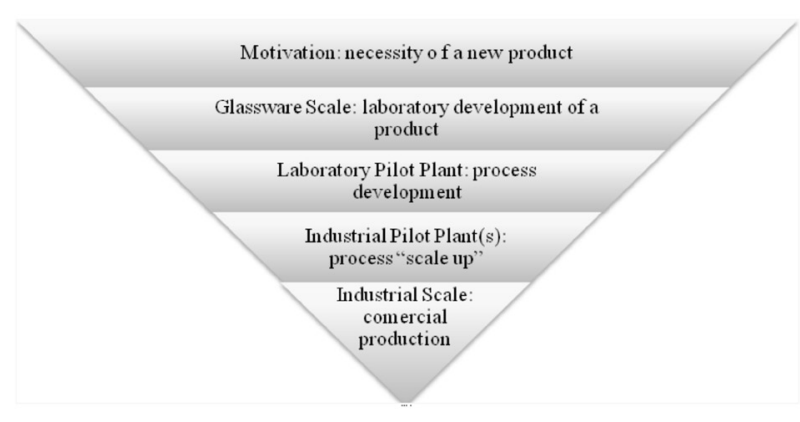

Figure 1. Different steps during a product/process development.

\section{Motivation: Why to Develop a Biodiesel Alternative Production Process}

In the last decades imperative concerns related to energy supply security and global climate change required a largescale substitution of petroleum-based fuels. ${ }^{1,2}$ Due to their functional similarity to petroleum-based fuel, ${ }^{3-6}$ biofuels obtained from triglycerides (see Figure 2), such as diesellike hydrocarbons obtained by thermocatalytic cracking or hydrocracking, ${ }^{7-9}$ as well as mono-alcohol fatty acid esters produced by alcoholysis, have become very attractive alternatives for diesel engines. ${ }^{10}$ Recently, the use of fatty acid methyl or ethyl esters (FAME or FAEE), largely known as biodiesel, has been highlighted in different countries, such as Brazil, ${ }^{11}$ USA and European Community, as the main alternative for large-scale substitution of diesel fuel. ${ }^{12}$

Although both routes to produce biodiesel are relatively simple chemical reactions (transesterification of triglycerides or esterification of fatty acids, Figure 2), they have several drawbacks, mainly related to catalyst efficiency and water and energy consumption. ${ }^{14}$ Indeed, since 1937 when the first patent regarding biodiesel production was deposited,${ }^{15}$ the widespread technology to produce biodiesel from triacylglycerides is alkaline transesterification. ${ }^{1}$ This technology is associated to soap formation, especially when the raw material contains more than 0.5 mass $\%$ in free fatty acids or 1 mass $\%$ in water. The presence of soaps leads to stable emulsions, consuming large amounts of water and energy to purify biodiesel. This fact makes mandatory to use almost edible grade oils which reduces the economical feasibility of biodiesel. Indeed, nowadays the oil cost is up to $80 \%$ of the total production cost of the biofuels. ${ }^{1}$ On the other hand, the production costs could be dramatically decreased using low-grade raw material, such as: acid stocks produced during physical neutralization of fats and oils; domestic or industrial sludge; poultry, porcine or cattle slaughterhouse wastes; ${ }^{1}$ algae bioreactors; ${ }^{16}$ or nonedible oils, such as from palm-trees ${ }^{17}$ or jatropha ${ }^{18}$ species. Besides, these low cost fatty materials would address the so called trilemma food/energy/environmental, which has recently being discussed in important publications. ${ }^{19}$ When we started our work, the main important alternative was the use of Brönsted acid catalysts, such as sulfuric or hydrochloric acids, which not only avoid the formation of soaps but also catalyze the esterification of free fatty acids. ${ }^{20}$ However, they have low activity for transesterification, taking longer times to convert raw materials into biodiesel with high reaction yields..$^{21}$ On the other hand, some attempts to use heterogeneous catalytic systems in

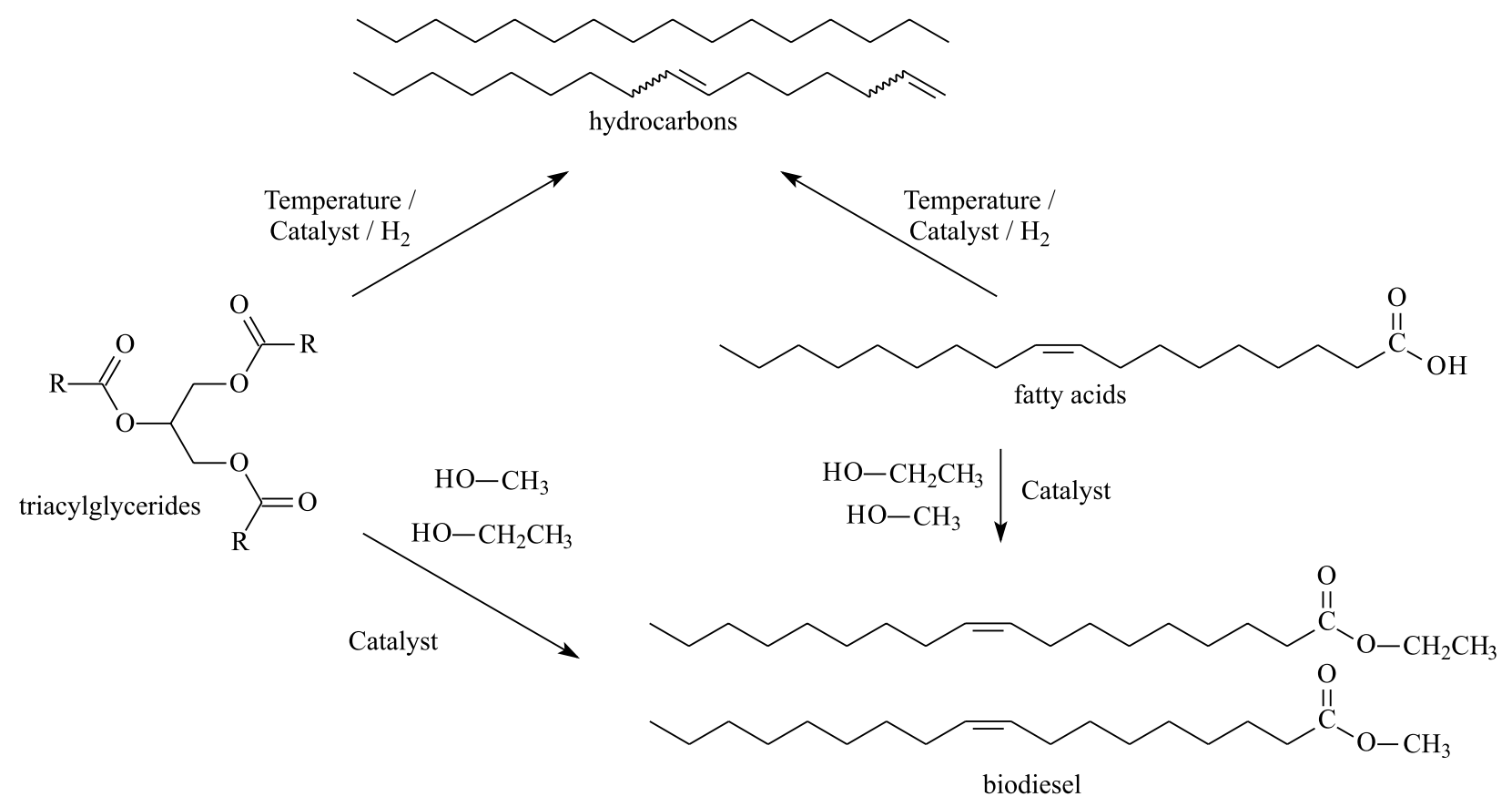

Figure 2. Biofuels (hydrocarbons and biodiesel) obtained from triacylglycerides and fatty acids. Adapted from reference 13. 
alcoholysis of triacylglycerides had also been made using several compounds of main metals, especially from groups $1,2,12,13,14$, and 15 , such as hydroxides, carbonates, oxides and alkoxides. ${ }^{22-24}$ However, these catalysts showed relatively slow reaction rate when compared with the traditional Brönsted homogeneous alkali or acid ones.

Thus, we decided to develop an alternative catalytic process with potential application in the preparation of biodiesel using raw materials with high free fatty acid contents. After trying some strong basic ${ }^{25}$ and acid $^{26,27}$ Lewis catalysts, we decided also to focus on mild Lewis acid metal compounds, which were fairly studied for this process.

\section{Getting Started: Screening Lewis Acid Metal Complexes in Homogeneous Conditions}

Our first approach was testing different Lewis metal complexes of the type $\mathrm{M}$ (3-hydroxy-2-methyl-4-pyrone) ${ }_{2}$, where $\mathrm{M}$ is $\mathrm{Sn}^{2+}, \mathrm{Zn}^{2+}, \mathrm{Cd}^{2+}$ and $\mathrm{Hg}^{2+}$, under homogeneous mild conditions and compare their activity with $\mathrm{NaOH}$ and $\mathrm{H}_{2} \mathrm{SO}_{4}{ }^{28}$ The reactions were carried out in simple glassware apparatus composed of a $50 \mathrm{~mL}$ two-neck round botton flask with a Allihn condenser. The reaction mixtures were kept under gentle reflux (approximately $60{ }^{\circ} \mathrm{C}$ ) and magnetic stirring for a desired time. It was observed, as can be depicted from Figure 3, that the different complexes were more active than both traditional acid and alkaline Brönsted catalysts and that the activity order $\left(\mathrm{Sn}^{2+}>>\right.$ $\mathrm{Zn}^{2+}>\mathrm{Pb}^{2+} \cong \mathrm{Hg}^{2+}$ ) was in accordance to the Lewis acidity order of the metals.

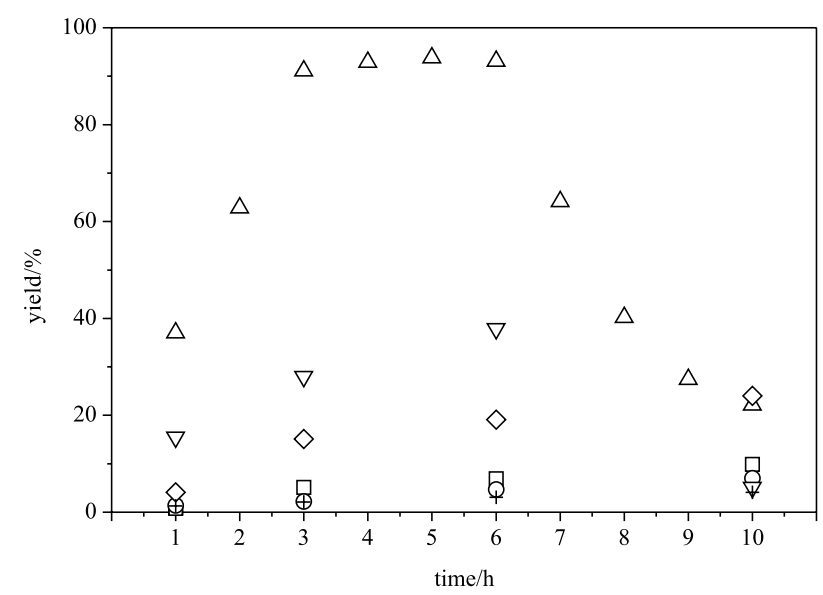

Figure 3. Transesterification of soybean oil with methanol using $\mathrm{NaOH}(\square), \mathrm{H}_{2} \mathrm{SO}_{4}(\mathrm{O}), \mathrm{Sn}\left(\mathrm{C}_{6} \mathrm{H}_{5} \mathrm{O}_{3}\right)_{2}(\triangle), \mathrm{Pb}\left(\mathrm{C}_{6} \mathrm{H}_{5} \mathrm{O}_{3}\right)_{2}(\diamond)$, $\mathrm{Hg}\left(\mathrm{C}_{6} \mathrm{H}_{5} \mathrm{O}_{3}\right)_{2}(+)$ and $\mathrm{Zn}\left(\mathrm{C}_{6} \mathrm{H}_{5} \mathrm{O}_{3}\right)_{2}(\nabla)$ as catalysts. Adapted from reference 28 .

To understand the mechanism of this reaction, the $\mathrm{Sn}^{2+}$ catalyst precursor was tested using different vegetable oils and alcohols. Indeed, it was chosen a variety of vegetable fats and oils, such as andiroba (Carapa guianensis), babassu (Orbignia sp.), palm tree (Elaeis sp.), piqui (Caryocar sp.) and soybean (Glycine max), containing fatty acids with different alkyd-chain lengths and unsaturation degree..$^{29}$ Under identical reaction conditions, it was observed that the reaction activities are strongly influenced by the composition of the oil or fat. In fact, the experiments showed that the methanolysis is favoured by the presence of unsaturations in the carbonic chain and decreases with its length. On the other hand, the alcoholysis of soybean oil in the presence of $\mathrm{Sn}^{2+}$ under identical conditions were also studied using different alkyl-chain alcohols such as methanol, ethanol, propanol, iso-propanol, $n$-butanol, tert-butanol and cyclohexanol under similar reaction conditions. It was verified that the catalytic activities are strongly dependent on the nature of the alcohol. Indeed, it was observed for linear alcohols that the reaction activities decrease when increasing the chain length. When comparing a linear and a branched alcohol with the same number of carbons was observed that for the second ones the activity decreases drastically. These results strongly suggest that a steric effect is controlling the catalytic activity. ${ }^{29}$

Because of these previously described results, we assumed that the transesterification probably follows a mechanism similar to those proposed for poly-esterification reactions catalyzed by divalent metals, as described in Figure $4 .{ }^{29}$ Using electrospray ionization mass spectrometry of a solution of $\operatorname{Sn}\left(\mathrm{C}_{6} \mathrm{H}_{5} \mathrm{O}_{3}\right)_{2}$ dissolved in 1-butyl-3metilimidazolium tetrafluoroindate we could observe that in the presence of methanol, the catalytic active site (specie 2 in Figure 4) is formed, ${ }^{30}$ allowing the coordination of a carbonyl containing compound (triacylglyceride, diacylglyceride, monoacylglyceride or the fatty acid). It is reasonable to state that this coordination would increase the polarization of the carbonyl compound and, thus, facilitating a nucleophilic attack by the alcohol (specie $\mathbf{3}$ in Figure 4). After forming the four center transition state $\mathbf{4}$, the desired biodiesel (methyl ester) is produced.

\section{Developing a Catalytic System with Tech- nological Potential using Acid Lewis Metal Compounds}

Despite of the excellent results obtained with these Lewis acid metal compounds, it is important to highlight that these catalysts had an importat technological drawback: they remained dissolved in the reaction medium, making difficult to recover and reuse them. For this reason, the direct substitution of homogeneous Brönsted catalysts (for instance, $\mathrm{NaOH}$ or $\mathrm{NaOCH}_{3}$ ) in the industrial process by these metal complexes is unthinkable. Thus, in sequence 


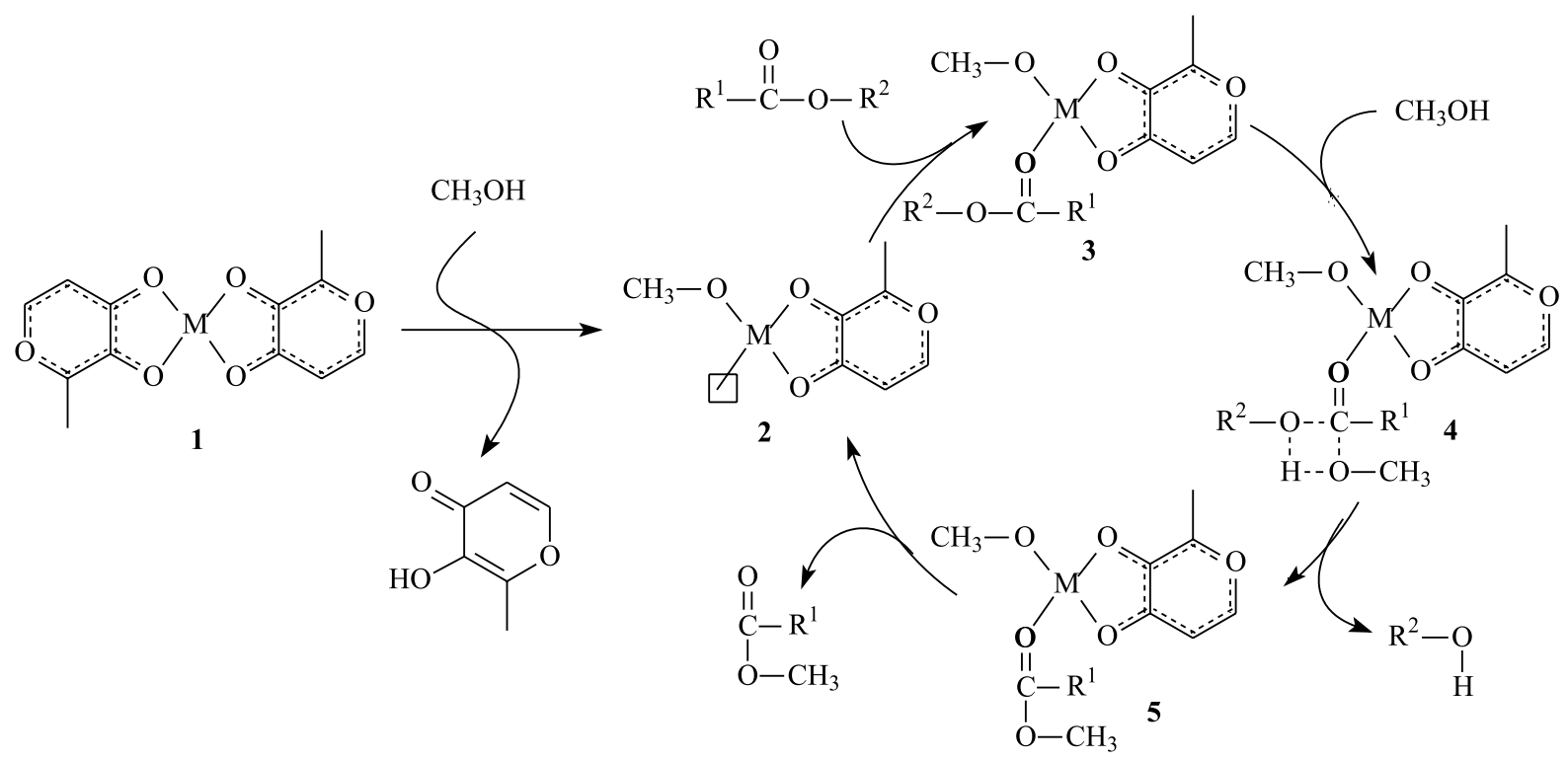

Figure 4. Proposed mechanism for alcoholysis of triacylglycerides using Lewis acid metal complexes as catalyst precursors. Adapted from references 29 and 30.

we started to develop a multiphase catalytic system using the Lewis acid metal divalent cation as active specie, searching for a system where the catalyst and the product were obtained in different phases at the reaction end.

Our first approach was the immobilization of the tin complex in a DOWEX ${ }^{\circledR}$ acid resin. ${ }^{31}$ The chemical adhesion of the tin complex to the acid resin was achieved by keeping in contact the insoluble organic resin with a DMSO solution of the complex. After a reaction of the tin complex with the sulfonic acid group of the resin, occurs the protonation and elimination of one molecule of the ligand and the complex remains coordinated to the sulfonate group. Unfortunately, when the resulting material was evaluated as heterogenized catalyst, using the same batch reactor described for the experiments with the Lewis acid complexes, it was observed a very low reaction yield $(0.5 \%)$, half the value obtained using the starting resin. ${ }^{31}$ It is worth to mention that the amount of tin anchored in the resin, as well as all other reaction parameters, was approximately the same as used in homogeneous conditions. Thus, it became clear that the interaction of the tin complex with the resin probably leads to a deactivation of the acid sites of both the resin and the complex.

Ionic liquids, especially those derived from dialkylimidazolium cation, have been used in several fields, such as electrochemistry ${ }^{32}$ and catalysis, ${ }^{33}$ because of their interesting physical-chemical behavior. ${ }^{34}$ Regarding the use of metal compounds as catalyst, ionic liquids have been described as excellent solvents to obtain bi-phase catalytic system due to their high efficiency to stabilize intermediates and avoid metal leaching. Then, we tried to anchor the tin Sn(3-hydroxy-2-methyl-4-pyrone) complex in the ionic liquids buthyl-methylimidazolium tetrachloroindate ${ }^{30}$ and buthyl-methylimidazolium hexafluorophosphate ${ }^{31}$ to obtain a two-phase catalytic system. A mixture of the tin complex, ionic liquid, methanol and soybean oil was kept in reflux for $1 \mathrm{~h}$. At the end, the reaction was quenched by adding water and a good separation of three phases was achieved: the upper layer contained the fatty acid methyl esters, the middle one was composed of water and hydroxyl compounds, and the bottom layer contained the ionic liquid and the catalyst; all separable by simple decantation. The ionic liquid was reused up to four times in both cases and was observed that in the first run the catalytic activity of the tin complex in this multiphase system was almost the same observed in homogeneous conditions, using similar time, temperature and oil:alcohol:tin molar ratio. However, when we tried to reuse the ionic phase containing the tin complex, the reactions yield drastically decreased with each new substrate charge, dropping to almost zero in the third recycling experiment. ${ }^{30,31}$ By ESI-MS analysis of the different phases, before and after catalysis, we could see that the tin fragments remain in the ionic liquid phase and was not detected in the other phases, strongly indicating that no leaching took place. However no sign of the starting tin compound or the catalytic active specie was noted, suggesting that they were decomposed and that this decomposition is probably the reason for the loss of the catalytic activity noted in the recycling experiments. ${ }^{30}$ Although it was possible to obtain an almost pure biodiesel phase and that a simple decantation was enough 
to isolate the desired product, the limitation of recycling the catalytic system compromises any industrial use of it, because of its high price when compared to traditional alkaline one. ${ }^{30,31}$ After we failed to obtain a recyclable multi-phase system anchoring the tin complex to an ionic liquid or to an organic solid phase that could keep the same catalytic activity observed in homogeneous conditions, we decided to prepare heterogeneous materials using the same metal. Our first attempt was to prepare $\mathrm{SnO}$ by calcinating $\operatorname{Sn}$ (acetylacetonate) $)_{2}$ and test it as a catalyst for the soybean oil transesterification in a batch system, using the same glassware as used for testing the soluble metal complexes. ${ }^{31} \mathrm{SnO}$ showed a good catalytic activity and conversions of up to 56 and $93 \%$ were obtained after 1 and $3 \mathrm{~h}$, respectively, and the solid could be isolated by simple filtration of the mixture at the end of the reaction. The recovered solid was used three more times, under the same reaction conditions, and the catalytic activity was totally conserved. ${ }^{31}$

Then, we prepared different mixed oxides of the type $\left(\mathrm{Al}_{2} \mathrm{O}_{3}\right)_{0.8}(\mathrm{SnO})_{0.2-\mathrm{x}}(\mathrm{ZnO})_{\mathrm{x}}(0.2 \leq \mathrm{x} \leq 0)$, from the co-precipitation of aluminum, tin and zinc hydroxides followed by calcinations. ${ }^{35}$ These new materials were tested for transesterification of different vegetable oils and several alcohols, including branched and linear ones, in the same batch apparatus described for the homogeneous catalytic systems. We observed that all materials have similar catalytic activity, with conversion yields up to $80 \%$ in $4 \mathrm{~h}$ for the methanolysis of soybean oil. The influence of the alcohol and acylglyceride alkyd chains in the reaction yield was found to be approximately the same as observed for the tin complex in homogeneous conditions, suggesting a similar mechanism. As observed for $\mathrm{SnO}$, it was also possible to recycle the catalysts at least four times without apparent loss of their catalytic activity.

Finally, we tested different metal oxides in the esterification of fatty acids with methanol. Indeed, fine powdered metal oxides were added with soybean fatty acids in a stainless steel autoclave and kept under magnetic stirring for the desired time at the chosen temperature. It was observed that after $3 \mathrm{~h}$ the reaction achieved an equilibrium with a yield ranging from 80 to $90 \%$, according to the reaction conditions, and that the decreasing order for catalysts activities was: $\mathrm{Al}_{2} \mathrm{O}_{3}>\mathrm{SnO}>$ $\left(\mathrm{Al}_{2} \mathrm{O}_{3}\right)_{8}(\mathrm{SnO})_{2}>\left(\mathrm{Al}_{2} \mathrm{O}_{3}\right)_{8}(\mathrm{ZnO})_{2}{ }^{36,37}$ This could be directly correlated with the different surface textures (acidity and area) of the studied catalysts. It was also observed that tin oxide could be recycled up to ten times without any significant loss in its activity. ${ }^{36}$ The high reaction yields for both transesterification of triacylglicerides and esterification of fatty acids with different alcohols, as well as the easy separation from products and good recycling results, strongly indicated that these metal oxides had a good potential to be used to obtain biodiesel from acid stocks. However, all these experiments were still done in batch systems using fine powdered oxides, which are very far away from something economically profitable feasible in an industrial scale.

\section{Developing a Industrial Process using Heterogeneous Fixed Bed Reactor}

The exiting results obtained with heterogeneous metal oxides in batch systems leaded us to start developing an industrial process. After evaluating several reactor design possibilities, we decided to develop a fixed bed tubular continuous reactor. The main reason for this decision was the easiness of its operation using liquid substrates and heterogeneous catalysts when compared with other types of reactors. ${ }^{38}$ It is important to note that some other groups have also tried to use continuous tubular reactor for the alcoholysis of triacylglycerides, such as supported guanidines, ${ }^{39-41}$ titanium and zirconium oxides modified with sodium hydroxide, ${ }^{38}$ and calcium carbonate $^{42}$ or hydrotalcites of the type $\mathrm{KF} / \mathrm{Ca}-\mathrm{Mg}-\mathrm{Al}{ }^{43}$ However, important drawbacks related to deactivation of the catalysts because of irreversible reaction of guanidines with free fatty acids or alkaline metal leaching have been reported.

Indeed, in this kind of equipment the catalyst, usually extruded into pellets, remains fixed in the reactor and the fluid is flowed throughout the particles. After a mass transfer from the fluid into the catalyst surface and the reactant adsorption in the active sites, the reaction occurs. Thus, the products desorption takes place and the resulting mixture leaves the reactor. Then, we designed and built a pilot plant with a continuous tubular reactor, as shown in Figure 5, with an automatic inset flow and temperature control. Note that a complete separation of biodiesel from the alcohol phase as shown in Figure 5 is achieved only when methanol is used. For ethanol and alcohols with more carbons a distillation step of these reagents is needed to achieve a complete separation of the biodiesel from glycerin.

In order to avoid any transport of the catalyst by the fluid flow that could result in important lose of mass, as well as could plug the tubular reactor exit, it is not suitable to use the metal oxides as fine powder as we performed in the batch experiments. For this reason, the next step was to prepare pelletized catalysts in order to properly hold them in the fixed bed reactor. Thus, after calcining the metal hydroxides at $500{ }^{\circ} \mathrm{C}$ under air, the obtained 


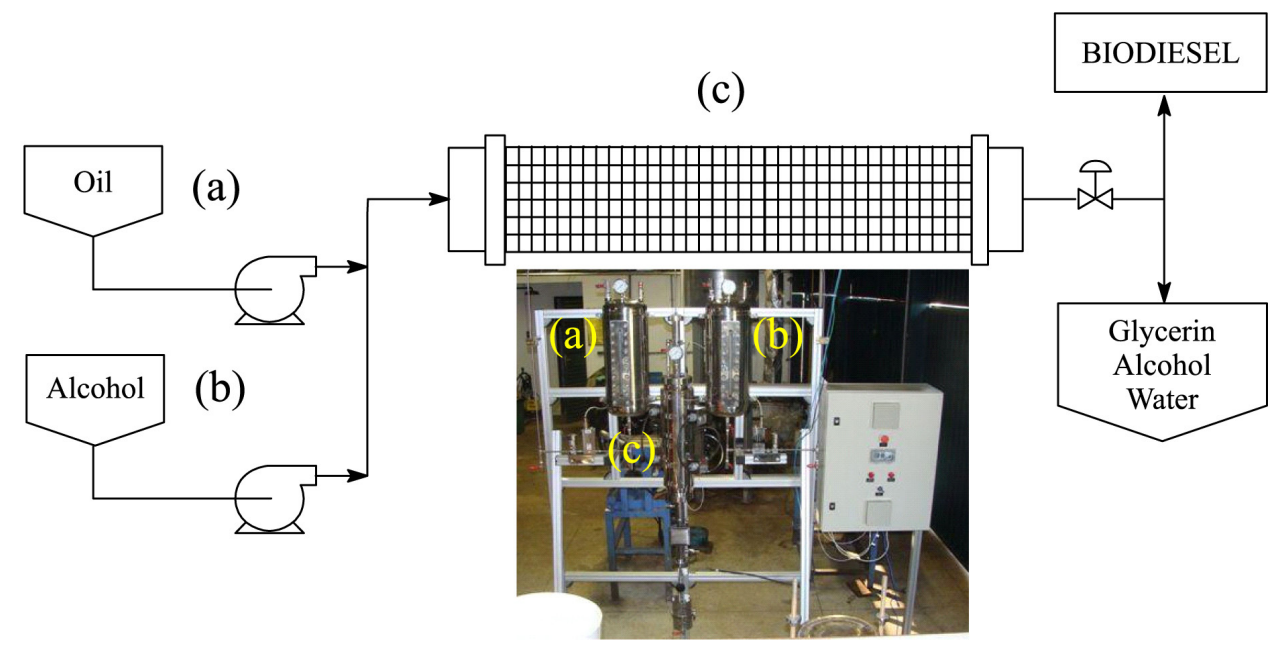

Figure 5. Scheme and picture the pilot plant designed to produce biodiesel using heterogeneous catalysts operating in a continuous flow: (a) fatty material stock, (b) alcohol stock and (c) tubular reactor.

powders were grounded and sieved to isolate particles with small $(<250 \mathrm{~mm})$ and regular size. Then, the powder was mixed with reagent grade starch and water to obtain a homogeneous paste, which after extruded and calcined at $500{ }^{\circ} \mathrm{C}$ under air leaded to pellets with approximately $1 \mathrm{~cm}$ long and $2 \mathrm{~mm}$ diameter. In Figure 6 is depicted the mixed oxides as starting calcined fine powder and the obtained extruded pellets before and after calcination.

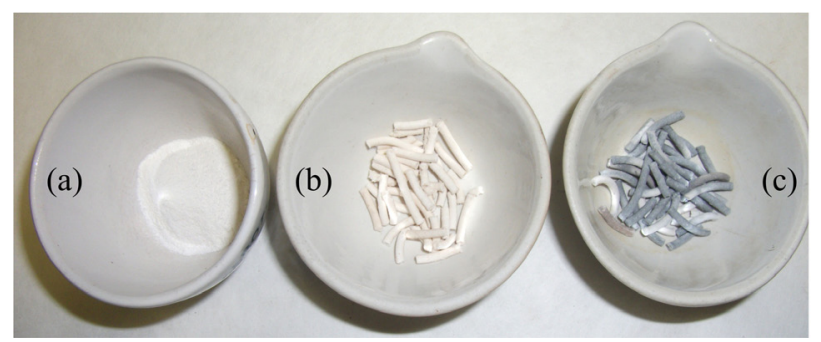

Figure 6. Developing mixed oxides suitable to be used in the fixed bed reactor: (a) starting calcined fine powder; obtained extruded pellet before (b) and after (c) calcinations.

The final pellets were placed into the tubular reactor as a $30 \mathrm{~cm}$ long column $(2.65 \mathrm{~kg})$. The reactor was flowed with soybean oil $\left(168 \mathrm{~g} \mathrm{~h}^{-1}\right)$ and methanol or ethanol $\left(89 \mathrm{~g} \mathrm{~h}^{-1}\right)$ with the temperature fixed at $100{ }^{\circ} \mathrm{C}$ and the results are shown in Figure 7. As can be seen in Figure 7, it is possible to convert soybean oil in up to $80 \%$ yield in the case of methanol and $40 \%$ for ethanol. Increasing the temperature to $180^{\circ} \mathrm{C}$, it was possible to ethanolise soybean oil with yields up to $90 \%$. It is important to note that after a steady state is achieved the conversions remained constant with time. It is also worth to mention that the fixed bed remained active for more than $200 \mathrm{~h}$, showing no catalyst leaching or deactivation, and so far was not possible to determine its overall productivity.

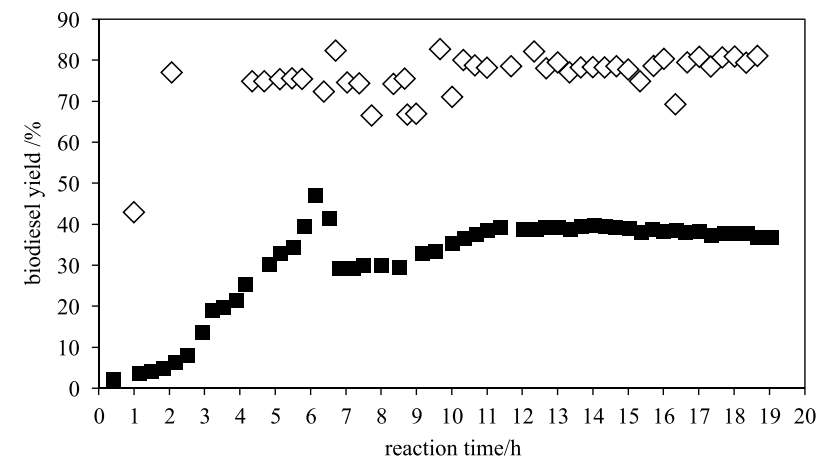

Figure 7. Alcoholysis of soybean oil $\left(168 \mathrm{~g} \mathrm{~h}^{-1}\right)$ and with methanol $\left(\diamond, 89 \mathrm{~g} \mathrm{~h}^{-1}\right)$ or ethanol $\left(\boldsymbol{\square}, 89 \mathrm{~g} \mathrm{~h}^{-1}\right)$, at $100^{\circ} \mathrm{C}$, in a continuous tubular reactor using a fixed bed of $\left(\mathrm{Al}_{2} \mathrm{O}_{3}\right)_{8}(\mathrm{ZnO})_{2}$ pellets $(2.65 \mathrm{~kg})$.

\section{Final Remarks}

As related along this paper, in the last 10 years we have focused in the development of an alternative process suitable to produce biodiesel using acid Lewis metal compounds. This effort directly involved 10 undergraduate students, 3 master students, 3 doctoral students in chemistry and 1 post-doctoral researcher, resulting in 10 research papers and 1 patent and spending approximately U\$ 0.5 million. Of course, this research project has resulted also in side studies involving the developing of analytical methods, biodiesel raw materials and biodiesel purification and modifications, which have also resulted in many other scientific publications and human resource formation.

Going back to the inverted pyramid described in Figure 1, after all this effort we have only successfully achieved step 3 , and we are still missing scaling up the pilot plant and starting up a commercial production. However, from this step we cannot advance without the participation, interest and investment of a company. Nevertheless, 
regarding the biodiesel industry that have been installed in Brazil in the last 7 years, $100 \%$ still use the same process developed back to 1937 in Belgium and probably will not be interested in investing in any process change until a large profit is obtained with the actual imported technology. Unfortunately, this is not an isolated case: there is a large distance between what we are able to develop in terms of science and technology in Brazil and what our industry would take risk and start up a commercial use of it.

\section{Acknowledgments}

We would like to thank Coordenação de Aperfeiçoamento de Pessoal de Nível Superior (CAPES), Conselho Nacional de Desenvolvimento Científico e Tecnológico (CNPq), Fundação de Apoio à Pesquisa do Distrito Federal (FAPDF) and Fundação Banco do Brasil for partial financial support. P. A. Z. Suarez and F. M. Silva are indebted to CNPq for their research fellowships.

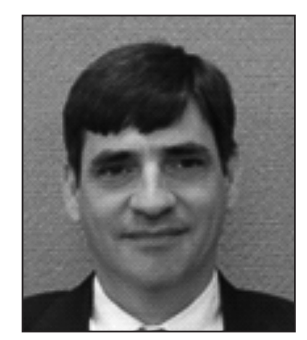

Paulo A. Z. Suarez was born in Quarai, RS, Brazil. He has studied Chemical Engineering at the Universidade Federal do Rio Grande do Sul (UFRGS), where he has also obtained his MSc degree in Chemistry and his PhD degree in Material Science. In 1998 he spent one-year term at the Université Louis Pasteur (Strasburg, France) as part of his PhD studies. He is an Associate Professor in the Institute of Chemistry at the Universidade de Brasilia since 2001 and a Researcher of the National Council for Scientific and Technological Development (CNPq, an Agency of the Ministry of Science, Technology and Innovation of Brazil) since 2003. He was a Visiting Professor at Stanford University and a Visiting Scientist at the USDA/ARS/NCAUR Laboratory. His research interests are focused on catalysis, with emphasis on the application to biomass and petroleum conversion into materials and fuels. He is author and co-author of over 80 scientific publications and 12 patents.

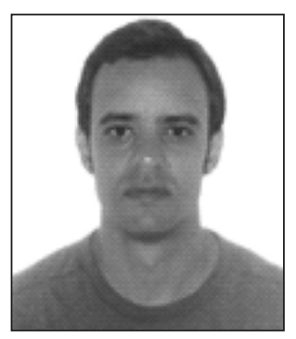

Fabio M. da Silva was born in Porto Alegre, RS, Brazil. He has graduated in Chemical Engineering at the Universidade Federal do Rio Grande do Sul (UFRGS). He has received his $M S c$ and $P h D$ degrees in Chemical Engineering from the Universidade Estadual de Maringá
(UEM), Paraná, PR, Brazil. He is an Associate Professor in the Institute of Chemistry at Universidade de Brasília $(U n B)$ since 2012. His research interests are focused on wastewater treatment and catalysis, with emphasis on biodiesel.

\section{References}

1. Suarez, P. A. Z.; Santos, A. L. F.; Rodrigues, J. P.; Alves, M. B.; Quim. Nova 2009, 32, 768.

2. Pinto, A. C.; Guarieiro, L. L. N.; Rezende, M. J. C.; Ribeiro, N. M.; Torres, E. A.; Lopes, W. A.; Pereira, P. A. P.; de Andrade, J. B.; J. Braz. Chem. Soc. 2005, 16, 1313.

3. De Oliveira, E.; Quirino, R. L.; Suarez, P. A. Z.; Prado, A. G. S.; Thermochim. Acta 2006, 450, 87.

4. Sharma, B. K.; Suarez, P. A. Z.; Perez, J. M.; Erhan, S. Z.; Fuel Process. Technol. 2009, 90, 1265.

5. Suarez, P. A. Z.; Moser, B. R.; Sharma, B. K.; Erhan, S. Z.; Fuel 2009, 88, 1143.

6. Doll, K. A.; Sharma, B. K.; Suarez, P. A. Z.; Erhan, S. Z.; Energy Fuels 2008, 22, 2061.

7. Lima, D. G.; Soares, V. C. D.; Ribeiro, E. B.; Carvalho, D. A.; Cardoso, E. C. V.; Rassi, F. C.; Mundim, K. C.; Rubim, J. C.; Suarez, P. A. Z.; J. Anal. Appl. Pyrolysis 2004, 71, 987.

8. Santos, A. L. F.; Martins, D. U.; Iha, O. K.; Ribeiro, R. A. M; Quirino, R. L.; Suarez, P. A. Z.; Bioresour. Technol. 2010, 101, 6157.

9. Quirino, R. L.; Tavares, A. P.; Tavares, A. P.; Peres, A. C.; Rubim, J. C.; Suarez, P. A. Z.; J. Am. Oil Chem. Soc. 2009, 86, 167.

10. Suarez, P. A. Z.; Meneghetti, S. M. P.; Meneghetti, M. R.;Wolf, C. R.; Quim. Nova 2007, 30, 667.

11. Suarez, P. A. Z.; Meneghetti, S. M. P.; Quim. Nova 2007, 30, 2068.

12. Pousa, G. P. A. G.; Santos, A. L. F.; Suarez, P. A. Z.; Energ. Pol. 2007, 35, 5393.

13. Brandao, R. F.; Quirino, R. L.; Mello, V. M.; Tavares, A. P.; Peres, A. C.; Guinhos, F.; Rubim, J. C.; Suarez, P. A. Z.; J. Braz. Chem. Soc. 2009, $20,954$.

14. Dupont, J.; Suarez, P. A. Z.; Meneghetti, M. R.; Meneghetti, S. M. P.; Energy Environ. Sci. 2009, 2, 1258.

15. Chavanne, G.; BE pat. 422,877 1937. (CA 1938, 32, 4313).

16. Suarez, P. A. Z.; Pinto, A. C.; J. Braz. Chem. Soc. 2011, 22 , 2023.

17. Alves, M. B; Medeiros, F. C. M.; Suarez, P. A. Z.; Ind. Eng. Chem. Res. 2010, 49, 7176.

18. Oliveira, J. S.; Leite, P. M.; De Souza, L. B.; Mello, V. M.; Silva, E. C.; Rubim, J. C.; Meneghetti, S. M. P.; Suarez, P. A. Z.; Biomass Bioenergy 2009, 33, 449.

19. Tilman, D.; Socolow, R.; Foley, J. A.; Hill, J.; Larson, E.; Lynd, L.; Pacala, S.; Reilly, J.; Searchinger, T.; Somerville, C.; Williams, R.; Science 2009, 325, 270. 
20. Keim, G. I.; US pat. 2,383-601 1945. (CA 1946, 40, 4617).

21. Freedman, B.; Pryde, E. H.; Mounts, T. L.; J. Am. Oil Chem. Soc.1984, 6, 1638.

22. Peterson, G. R.; Scarrach, W. P.; J. Am. Oil Chem. Soc. 1984, $61,1593$.

23. Suppes, G. J.; Bockwinkel, K.; Lucas, S.; Bots, J. B.; Mason, M. H.; Heppert, J. A.; J. Am. Oil Chem. Soc. 2001, 78, 139.

24. Gryglewicz, S.; Bioresour. Technol. 1999, 70, 249.

25. Faria, E. A.; Ramalho, H. F.; Marques, J. S.; Suarez, P. A. Z.; Prado, A. G. S.; Appl. Catal., A 2008, 338, 72.

26. Faria, E. A.; Marques, J. S.; Dias, I. M.; Andrade, R. D. A.; Suarez, P. A. Z.; Prado, A. G. S.; J. Braz. Chem. Soc. 2009, 20, 1732.

27. Brito, Y. C.; Mello, V. M.; Macedo, C. C. S.; Meneghetti, M. R.; Suarez, P. A. Z.; Meneghetti, S. M. P.; Appl. Catal., A 2008, $351,24$.

28. Abreu, F. R.; Lima, D. G.; Ham, E. H.; Einloft, S.; Rubim, J. C.; Suarez, P A. Z.; J. Am. Oil Chem. Soc. 2003, 80, 601.

29. Abreu, F. R.; Lima, D. G.; Ham, E. H.; Wolf, C.; Suarez, P. A. Z.; J. Mol. Catal. A: Chem. 2004, 209, 29.

30. Neto, B. A. D.; Alves, M. B.; Lapis, A. A. M.; Nachtigall, F. M.; Eberlin, M. N.; Dupont, J.; Suarez, P. A. Z.; J. Catal. 2007, 249, 154.

31. Abreu, F. R.; Alves, M. B.; Macedo, C. C. S.; Zara, L. F.; Suarez, P. A. Z.; J. Mol. Catal. A: Chem. 2005, 227, 263.

32. Suarez, P. A. Z.; Consorti, C. S.; de Souza, R. F.; Dupont, J.; Gonçalves, R. S.; J. Braz. Chem. Soc. 2002, 13, 106.
33. Consorti, C. S.; Umpierre, A. P.; de Souza, R. F.; Dupont, J.; Suarez, P. A. Z.; J. Braz. Chem. Soc. 2003, 14, 401.

34. Consorti, C. S.; de Souza, R. F.; Dupont, J.; Suarez, P. A. Z.; Quim. Nova 2001, 24, 830.

35. Macedo, C. C. S.; Abreu, F. R.; Tavares, A. P.; Alves, M. B.; Zara, L. F.; Rubim, J. C.; Suarez, P. A. Z.; J. Braz. Chem. Soc. 2006, 17, 1291.

36. Mello, V. M.; Pousa; G. P. A. G.; Pereira; M. S. C.; Dias, I. M.; Suarez, P. A. Z.; Fuel Process. Technol. 2011, 92, 53.

37. Mello, V. M.; Oliveira, F. C. C.; Fraga, W. G.; do Nascimento, C. J.; Suarez, P. A. Z.; Magn. Reson. Chem. 2008, 46, 1051.

38. McNeff, C. V.; McNeff, L. C.; Yan, B.; Nowlan, D. T.; Rasmussen, M.; Gyberg, A. E.; Krohn, B. J.; Fedie, R. L.; Hoye, T. R.; Appl. Catal., A 2008, 343, 39.

39. Schuchardt, U.; Lopes, O. C.; BR pat. 8202429 1984. (CA1984, 101, P93246).

40. Schuchardt, U.; Sercheli, R.; Vargas, R. M.; J. Braz. Chem. Soc. 1998, 9, 199.

41. Balbino, J. M.; de Menezes, E. W.; Benvenutti, E. V.; Cataluña, R.; Ebeling, G.; Dupont, J.; Green Chem. 2011, 13, 3111.

42. Hsieh, L.; Kumar, U.; Wu, J. C. S.; Chem. Eng. J. 2010, 158, 250.

43. Xiao, Y.; Gao, L.; Xiao, G.; Lv, J.; Energy Fuels 2010, 24, 5829.

Submitted: June 9, 2012

Published online: July 11, 2012 